\title{
AUTOPLÁGIO: UMA VIOLAÇÃO AO DIREITO À INTEGRIDADE INTELECTUAL?
}

\section{Alexander Perazo Nunes de Carvalho ${ }^{1}$ Anya Lima Penha de Brito ${ }^{2}$}

RESUMO: O presente artigo tem como escopo compreender o autoplágio, conceituando-o e trazendo um panorama acerca do seu entendimento em outros países. Após, passa-se a enfrentar os motivos que levam a existência cada vez mais frequente dos fenômenos do plágio e do autoplágio, em que pese a crescente divulgação acerca da vedação expressa do Conselho Nacional de Desenvolvimento Científico e Tecnológico (CNPq) e da Coordenação de Aperfeiçoamento de Pessoal de Nível Superior (CAPES) a tais institutos. Conclui-se que as limitações impostas por aludidos órgãos não afrontam o direito de personalidade do autor, em que pese o seu direito à integridade intelectual.

Palavras-Chave: Autoplágio. Plágio. Autor. Direito Personalidade. Integridade Intelectual.

\section{SELF-PLAGIARISMO: A VIOLATION OF THE RIGHT TO INTELLECTUAL INTEGRITY?}

\begin{abstract}
The purpose of this article is to understand self-plagiarism, conceptualizing it and providing a panorama about its understanding in other countries. After that, we are faced with the reasons that lead to the increasingly frequent existence of the phenomena of plagiarism and Self-plagiarism, in spite of the increasing dissemination about the express prohibition of the National Council of Scientific and Technological Development (CNPq) and the Coordination of Improvement of Higher Education Personnel (CAPES) to such institutes. It is concluded that the limitations imposed by such bodies do not confront the author's right of personality, in which he asks for his right to intellectual integrity.
\end{abstract}

Keywords: Self-plagiarism. Plagiarism. Whiter. Right Personality. Intellectual Integrity.

\footnotetext{
${ }^{1}$ Doutor (2013) e Mestre (2004) em Direito Constitucional pela Universidade de Fortaleza, com área de concentração em Direito Privado. Graduação em Direito pela Universidade Federal do Ceará (1998). Professor do Mestrado Acadêmico da Unichristus. Professor de Graduação do Centro Universitário Christus (Unichristus), da Universidade de Fortaleza (UNIFOR) e da Faculdade Luciano Feijão (Sobral/Ce). Professor Visitante da Universidade Potiguar, em Natal/RN. Assessor Jurídico-Chefe da Procuradoria de Justiça Militar da União, em Fortaleza/Ce. Tem experiência na área de Direito, com ênfase em Direito Civil e Direito do Consumidor, atuando principalmente nos seguintes temas: Civil - parte geral; obrigações; contratos; posse, propriedade privada, função socioambiental da propriedade, ecopropriedade e constitucionalização do direito privado. E-mail: perazo@globo.com. ORCID ID: https://orcid.org/0000-0003-1745-529

${ }^{2}$ Mestranda em Processo e Direito ao Desenvolvimento pelo Centro Universitário Christus (Unichristus). Bacharel em Direito pela Universidade de Fortaleza (Unifor). Advogada. E-mail: anyalpbrito@gmail.com. ORCID ID: http://orcid.org/0000-0002-9115-0148.
} 


\section{INTRODUÇÃO}

A evolução tecnológica e o fenômeno da globalização permitiram a disseminação do conhecimento, tornando-o mais democrático e acessível a todos em qualquer lugar do mundo. Ao mesmo tempo, essa evolução atrelada ao produtivismo científico, fez eclodir dois fenômenos, ressalte-se, totalmente rechaçados pelo meio acadêmico, quais sejam: o plágio e autoplágio.

O presente artigo tem como objetivo fazer um estudo do autoplágio contextualizandoo com o plágio, analisando-o à luz do direito da personalidade à integridade intelectual, questionando se a vedação da utilização de antigas publicações do autor, aprofundando-as e servindo de subsídio para novos trabalhos acadêmicos não corresponderia a uma limitação ao seu direito à integridade intelectual.

Demais disso, identificou-se que, apesar da ampla divulgação nos meios acadêmicos das formas corretas de realizar-se as citações de obras de terceiros e do surgimento de mecanismos capazes de identificar a similaridade entre textos é cada vez mais frequente a identificação de plágio, assim como do autoplágio.

Assim, no primeiro momento, fora realizado um estudo acerca do plágio, quais as suas formas de identificação e consequências. Constatou-se que não há um consenso mundial em torno da sua conceituação. Após, mostrou-se a figura do autoplágio, objeto principal deste trabalho, apresentando-se seu conceito e suas diversas formas de realizar-se.

Ademais, busca-se compreender se a limitação da utilização dos escritos já publicados pelo autor em nova publicação, sem a autocitação, seria uma forma de limitar o direito de personalidade do autor. Para tanto, foi realizado um estudo sobre os direitos de personalidade, destacando a sua conceituação, suas características. Apresentou-se ainda as espécies de direitos de personalidade, destacando o direito à integridade intelectual.

Por fim, enfrentou-se o autoplágio à luz do direito de personalidade à integridade intelectual, questionando-se se tal ingerência não seria um violador ao seu direito de personalidade sob o panorama de integridade intelectual.

Destaque-se ainda que o tema em questão foi enfrentado por meio de pesquisa bibliográfica, com suporte em livros e artigos. Acerca dos objetivos propostos, esta pesquisa foi delineada como descritiva documental. 


\title{
2 COMPREENDENDO O AUTOPLÁGIO E SEUS DESDOBRAMENTOS
}

Antes de iniciar um estudo acerca do autoplágio, mostra-se pertinente contextualizálo com o plágio. Segundo Otávio Afonso (2009, p. 121), o plágio versa:

\begin{abstract}
“[...] em apresentar como própria a obra intelectual produzida por outra pessoa", enquanto que a "contrafação equivale a reproduzir uma obra, sem autorização, independente do meio utilizado. Neste caso, ela atenta contra a individualidade da obra alheia, visando obter ilicitamente vantagem econômica. O contrafator não pretende ser reconhecido como autor da obra contrafeita"
\end{abstract}

Observa-se, portanto, que o plágio ocorre quando o autor faz uso de publicações de outrem como sua, sem identifica-las como de terceiro. Apesar de ser frequente no âmbito acadêmico, e sua realização ser passível de responsabilização penal, não há na legislação brasileira a terminologia ou alguma regulamentação específica acerca do tema. É um conceito em construção pelos doutrinadores e enfrentado em algumas decisões judiciais. (ZANINI, 2017, on-line).

Demais disso, o plágio relaciona-se à utilização indevida de material alheio como seu e, no Brasil, possui enquadramento jurídico na Lei n. ${ }^{\circ}$ 9.610/98, a qual declina-se a respeito dos direitos autorais e traz em seu texto a vedação à reprodução não autorizada de uma obra, denominando-a de contrafação. Relata-se ainda que o Código Penal, em seu art. 184, tipifica como crime a violação a direito autoral. (ZANINI, 2017, on-line).

Segundo Silmara Juny de Abrey Chinellato (2012, p.308), o ordenamento jurídico peruano foi o único ordenamento que trouxe em seu bojo a conceituação de plágio, por meio da Lei 13.714/61, em seu art. 124. Atualmente, aludido artigo foi revogado pelo Decreto Legislativo 822/96, que não mais regulamenta o plágio.

Para Marcelo Krokoscz (2014; p. 40-41), em que pesem as variadas denominações que o fenômeno plágio pode receber, tais como: meio-plágio, plágio cru, plágio integral, parcial e conceitual, plágio escrito, plágio civilizado, todos referem-se à utilização de texto de terceiro como se fosse seu.

No Brasil, o relatório da Comissão de Integridade de Pesquisa do Conselho Nacional de Desenvolvimento Científico e Tecnológico (CNPq), instituída pela Portaria PO-085-2011 (BRASIL, 2011, on-line), conceitua o plágio como: 
Plágio: consiste na apresentação, como se fosse de sua autoria, de resultados ou conclusões anteriormente obtidas por outro autor, bem como de textos integrais ou de parte substancial de textos alheios sem os cuidados detalhados nas Diretrizes. Comete igualmente plágio quem se utiliza de ideias ou dados obtidos em análises de projetos ou manuscritos não publicados aos quais teve acesso como consultor, revisor, editor ou assemelhado.

Contudo, a depender do país, o plágio assume contornos distintos. Em países da língua inglesa, há uma cultura forte acerca da propriedade de ideias e expressões escritas. Nesses países, o plágio pode ser considerado roubo. Nos países orientais, por sua vez, a noção de propriedade intelectual é um conceito coletivo e não particular (VASCONCELOS, 2007, online).

Assim, diante das inconsistências em torno da conceituação do plágio, desde a sua conceituação, do momento em que ocorre e formas de manifestação, mostra-se pertinente uma atualização conceitual acerca do assunto para buscando-se uma definição universal a seu respeito. (KROKOSCZ,2014; p.129).

Nesse sentido posiciona-se Richard Posner (2013, p. 15):

Lo primero que necesitamos es uma definicion, pero definir plagio no es tan fácil. Una definicion frecuente en lo diccionarios es incompleta: aunque por lo general presupondremos que el plagiario escribe, plagio puede darse no solo de palavras sino tambien de musica, cuadros o ideas. Peca, además, esta definicion de inexactitud: depues veremos que puede haber plagio sin robô. Y es imprecisa, porque no queda claro em que consisya el robô cuando nadie está sustrayendo nada a nadie sino que se limita a sacar uma copia. ${ }^{3}$

Existe ainda a figura do autoplágio, o qual, segundo o Conselho Nacional de Desenvolvimento Científico e Tecnológico (CNPq), Portaria PO-085-2011 (BRASIL, 2011, on-line): "seria um tipo de fraude cientifica, que consiste na apresentação total ou parcial de textos já publicados pelo mesmo autor, sem as devidas referências aos trabalhos anteriores".

Aludido fenômeno pode ocorrer de duas formas: seja por meio da republicação, quando ocorre a reprodução de um trabalho anterior do autor já publicado, sem a autocitação e, algumas vezes, sem qualquer alteração; ou pela redundância, quando o mesmo trabalho é

\footnotetext{
${ }^{3}$ Tradução livre: 'A primeira coisa que precisamos é de uma definição, mas definir plágio não é tão fácil. Uma definição frequente nos dicionários é incompleta: embora geralmente assumamos que o plagiador escreve, o plágio pode ocorrer não apenas de palavras, mas também de música, imagens ou idéias. Além disso, essa definição de imprecisão está errada: depois veremos que pode haver plágio sem robó. E é impreciso, porque não está claro em que consiste o robô, quando ninguém está tirando nada de ninguém, apenas copiando'.
} 
fracionado e republicado como inédito em partes menores, como se original fosse. Neste caso ocorre o fenômeno denominado "trabalho salame".

Segundo Ernesto Spinak (2013, on-line):

O autoplágio não é uma violação do direito de autor, mas pode ser considerado um problema ético. Isto é comum quando um artigo é publicado em forma picada. Há alguns anos, os periódicos científicos aceitavam manuscritos em que a novidade do texto fosse de $50 \%$, mas atualmente a maioria exige que o material inédito seja pelo menos de $80 \%$. Estas situações são tratadas com diferentes critérios pelas diferentes associações profissionais e as áreas de pesquisa, desde a Administração e Economia até as Ciências Médicas e Biológicas.

Um dos maiores desafios acadêmicos é compreender os motivos que levam a um número crescente de obras plagiadas e autoplagiadas. Afirmam que o plágio tem ocorrido com mais frequência em razão da disseminação da informação em decorrência da globalização e do avanço das tecnologias, com o auxílio da Internet, que possibilita a disseminação das publicações a número de pessoas cada vez maior, permitindo com isso que sejam utilizadas por outros autores como se fossem manuscritos inéditos.

Nesse sentido posiciona-se Dib Guevara (2007, p.10), ao dispor:

Se por um lado o uso da tecnologia computacional facilitou o trabalho de
produção textual, com o desenvolvimento da rede mundial de computadores,
a internet, o uso privado deste recurso pelo público comum, tornou o acesso à
informação uma possibilidade incrível de obtenção e compartilhamento das
ideias produzidas por indivíduos particulares, bem como de acesso ao
conhecimento acumulado pela história da humanidade, desenvolvendo assim
a noção de "patrimônio comum", algo que nunca antes do ponto de vista da
disponibilidade e acesso à informação tinha sido tão rico e concreto.

Acerca do autoplágio, acredita-se que este esteja atrelado a uma cobrança crescente cada vez maior de publicações, gerando um fenômeno conhecido de produtivismo, em que se valoriza a quantidade de publicações em detrimento a qualidade/inovação das pesquisas. Assim, mostra-se pertinente uma análise acerca da limitação do uso pelo autor de textos anteriormente publicados por ele, se tal ingerência não seria um violador ao seu direito de personalidade sob o panorama de integridade intelectual. 


\section{UMA ANÁLISE DO DIREITO DE PERSONALIDADE À INTEGRIDADE INTELECTUAL}

Os direitos de personalidade estão inseridos no Código Civil em seus artigos 11 a 21. Tratam-se de direitos conferidos a toda e qualquer pessoa (física ou jurídica), propiciando o gozo de seus direitos e a possibilidade de adquirirem obrigações (GAGLIANO, 2018, p.44).

Para Maria Helena Diniz (2012, p.133-134):

A personalidade não é um direito, de modo que seria errôneo afirmar que o ser humano tem direito à personalidade. A personalidade é que apoia os direitos e deveres que dela irradiam, é objeto de direito, é o primeiro bem da pessoa, que lhe pertence como primeira utilidade, para que ela possa ser o que é, para sobreviver e se adaptar às condições do ambiente em que se encontra, servindolhe de critério para aferir, adquirir e ordenar outros bens.

Demais disso, sabe-se que os direitos de personalidade, previstos no Código Civil são numerus apertus, conforme dispõe o Enunciado 274 da IV Jornada de Direito Civil ${ }^{4}$, tendo em vista sua relação com o princípio da dignidade da pessoa humana, o qual trata-se de cláusula aberta, servindo de subsídio para novos direitos não expressos nos textos legais.

Dessa forma, inviável apresentar um conceito fechado acerca dos direitos de personalidade, tendo em vista que a preocupação maior é proteger a pessoa em si. Logo, sua natureza aberta permite ampliar a proteção aos direitos atípicos, não expressamente previstos, mas que são fundamentais para o exercício da vida de relações. (PERLINGIERI, 2002, p.156).

Podemos, então, compreendê-los como direitos subjetivos do ser humano, protegendoo em todas as feições que constituem a personalidade do seu titular, seja em seu aspecto físico, moral e intelectual, e atribuir-lhes as seguintes características: a extrapatrimonialidade, a generalidade, o caráter absoluto, a inalienabilidade, a imprescritibilidade e a intransmissibilidade.

Entende-se por extrapatrimonialidade, pela impossibilidade de determinar um conteúdo econômico direto; e por absoluto, pelo fato de serem oponíveis em face de todos, devendo a coletividade respeita-los; são inalienáveis, posto que não podem ser vendidos; são imprescritíveis, uma vez que não existe prazo para seu exercício e intransmissíveis e

\footnotetext{
${ }^{4}$ Os direitos da personalidade, regulados de maneira não-exaustiva pelo Código Civil, são expressões da cláusula geral de tutela da pessoa humana, contida no art. $1^{\circ}$, III, da Constituição (princípio da dignidade da pessoa humana). Em caso de colisão entre eles, como nenhum pode sobrelevar os demais, deve-se aplicar a técnica da ponderação.
} 
irrenunciáveis, posto que não podem sofrer limitações, salvo nos casos previstos em Lei. Alguns autores acrescentam ainda a essencialidade e preeminência, em razão da peculiaridade do seu objeto. (TEPEDINO, 2008, p.36-37).

São direitos conferidos a pessoa para resguardar os direitos que lhe são próprios, como exemplo, o direito à vida, o direito de ir e vir, o direito de privacidade, direito de imagem. Exige-se de terceiro uma conduta negativa, para o fim de não violar tais direitos. Demais disso, não se extinguem quando não utilizados (DINIZ, 2012, p. 136).

Assim, podem ser divididos em: integridade física (direito à vida, ao corpo, ao cadáver e à saúde); integridade moral (proteção à honra, liberdade, imagem e nome) e integridade intelectual (liberdade de pensamento, a autoria científica, artística e literária).

O primeiro consiste ao direito à vida e ao corpo, seja vivo ou morto; ao passo que o segundo refere-se a honra, à imagem e a identidade familiar e social; e o terceiro está relacionado a liberdade de pensamento e aos direitos do autor. (SILVA, 2016, on-line).

Como o presente trabalho tem como norte o estudo do autoplágio, o qual consiste na utilização do pesquisador de antigos trabalhos por ele elaborados, como se inédito fossem, haveria uma limitação ao estudo dos direitos da personalidade à luz da integridade intelectual.

Desse modo, nos dizeres de André Fasb (2010, on-line), o direito à integridade intelectual consiste: "no poder que as pessoas têm de vincular seu nome às produções de seu espírito, tendo a garantia de publicar, reproduzir e explorar, tal produção, punindo aqueles que dele se apropriarem indevidamente".

O que se discute é se a limitação ao aproveitamento dos escritos do pesquisador, exigindo que faça a autocitação de seus antigos trabalhos, para então dar andamento aos novos escritos, sob pena de ser acusado de autoplágio, não seria uma espécie de infração ao direito de personalidade à integridade intelectual, o que será analisado a seguir.

\section{ANÁLISE DO AUTOPLÁGIO À LUZ DA INTEGRIDADE INTELECTUAL}

Apresentou-se alhures a definição do autoplágio, indicando que se refere a uma prática do pesquisador em usar texto de sua autoria anteriormente publicado ou parte desses escritos em nova publicação, sem citá-lo ou indicá-lo formalmente. (COURY, 2012). 
Declinou-se ainda a respeito do direito à integridade intelectual, o qual permite ao autor o direito de liberdade de pensamento, garantindo-lhe o direito de publicar e reproduzir seus trabalhos.

Agora, passa-se a enfrentar a relação entre o autoplágio e o direito à integridade intelectual. Questiona-se: há violação desse direito, quando se limita que o pesquisador utilize de forma direta seus estudos, aprofundando-o e exigindo que os cite por meio da autocitação?

É importante destacar que o autor possui direito moral e patrimonial sobre a sua obra podendo dela dispor da maneira que lhe aprouver, conforme dispõem os artigos. 22 e 24 da Lei n. 9.610/1998 (Lei dos Direitos Autorais). Veja-se:

Art. 22. Pertencem ao autor os direitos morais e patrimoniais sobre a obra que criou.

Art. 24. São direitos morais do autor:

I - o de reivindicar, a qualquer tempo, a autoria da obra;

II - o de ter seu nome, pseudônimo ou sinal convencional indicado ou anunciado, como sendo o do autor, na utilização de sua obra;

III - o de conservar a obra inédita;

IV - o de assegurar a integridade da obra, opondo-se a quaisquer modificações ou à prática de atos que, de qualquer forma, possam

prejudicá-la ou atingi-lo, como autor, em sua reputação ou honra;

$\mathrm{V}$ - o de modificar a obra, antes ou depois de utilizada;

VI - o de retirar de circulação a obra ou de suspender qualquer forma de utilização já autorizada, quando a circulação ou utilização implicarem afronta à sua reputação e imagem;

VII - o de ter acesso a exemplar único e raro da obra, quando se encontre legitimamente em poder de outrem, para o fim de, por meio de processo fotográfico ou assemelhado, ou audiovisual, preservar sua memória, de forma que cause o menor inconveniente possível a seu detentor, que, em todo caso, será indenizado de qualquer dano ou prejuízo que lhe seja causado.

Para Carlos Alberto Bittar (1999; p.44):

Os direitos morais são os vínculos perenes que unem o criador à sua obra para a realização da defesa de sua personalidade. Como os aspectos abrangidos se relacionam à própria natureza humana e desde que a obra é emanação da personalidade do autor - que nela cunha, pois, seus próprios dotes intelectuais - esses direitos constituem a sagração, no ordenamento jurídico, da proteção dos mais íntimos componentes da estrutura psíquica do seu criador.

Entretanto, há autores que afirmam que os direitos pessoais (morais) em razão de sua natureza de direito da personalidade são inalienáveis e irrenunciáveis, e que somente os direitos patrimoniais podem ser cedidos (SIXTO, 2014).

Nesse sentido dispõe Plinio Cabral (2003, p.43): 
A sentença judicial pode proibir a circulação de uma obra, mas não pode atingir os direitos morais do autor, pois eles são irrenunciáveis e inalienáveis e, consequentemente, imunes a qualquer ataque ou restrição, mesmo por parte da justiça. Proibido um livro, o autor mantém sobre ele sua autoria, tendo todos os direitos morais que a lei confere. A obra proibida hoje, amanhã pode ser consagrada.

Demais disso, os direitos morais do autor sobre sua obra surgem a partir da sua criação, relacionando-se com seu direito de efetivar alterações em seus escritos ou de se contrapor a qualquer alteração, correspondendo ao direito de personalidade à integridade intelectual. Logo, não podem ser negociados, sob pena de ser anulado. (CABRAL, 2003; 44-45).

Poder-se-ia questionar se após publicação de uma obra em domínio público, esta poderia ser utilizada de forma livre. Plinio Cabral (2003, p.46) explica que:

O domínio público pressupõe a livre utilização da obra. Mas ela não é res derelicta, coisa abandonada para ser utilizada de qualquer forma. Ao contrário, a obra em domínio público é res omnium, que pertence a toda a sociedade. E o Estado é - ou deveria sê-lo - o guardião daquilo que é um bem comum. Por isso mesmo a lei atual repete a anterior quando diz que "compete ao Estado a defesa da integridade e autoria da obra caída em domínio público”.

Registre-se que a disposição dos direitos de propriedade, por sua vez, pode ocorrer por meio da assinatura pelo autor de um contrato de cessão, permitindo que seus escritos sejam publicados em periódicos ou livros. Em regra, o contrato firmado entre as partes prevê a limitação do seu uso, no todo ou em parte, em outra publicação (DINIZ; 2018).

Arremata Eduardo Diniz ao dispor que (2018; p. 203):

Tudo fica muito diferente quando o texto de origem envolve um contrato de cessão de direitos, caso da maioria dos periódicos. Nesses casos, o contrato assinado entre autor e entidade publicadora normalmente limita o seu uso, no todo ou em parte, por outra publicação. Assim, quando uma similaridade desse tipo é encontrada, o periódico tem obrigação de solicitar que o autor refaça os trechos similares, sob pena de sofrer um processo por apropriação indevida. Autores que têm dificuldade de entender a separação entre "autoria" e "propriedade" de uma obra intelectual se sentem ofendidos, por acreditarem que não estavam fazendo nada de errado. No entanto, ao assinarem contrato com a editora original, a questão deixa de ser meramente ética e passa a ser do direito comercial.

Assim, quando firmado contrato entre o autor e uma editora, deve-se compreender que esta adquire a propriedade do texto, permitindo-lhe vetar a utilização do manuscrito em nova obra de forma ipsis litteris.

Logo, não há que se falar em afronta ao direito personalíssimo à integridade intelectual, posto que ao firmar contrato ou termo com revista ou editora, o pesquisador dispõe 
do seu direito de propriedade dos seus escritos, mantendo-se intacto seu direito moral sobre a obra.

De todo modo, a ausência de uma regulamentação a respeito do percentual máximo aceitável para que uma obra se espelhe em um escrito anterior do próprio pesquisador, gera uma insegurança, induzindo o pesquisador a seguir nova linha de estudo em razão do medo de ser acusado de autoplágio, perdendo por certo credibilidade no meio editorial/acadêmico.

Com isso criam-se pesquisas superficiais que em nada acrescentam à ciência, com intuito eminentemente produtivista. Sabe-se que a ciência tem como função precípua disseminar conhecimento novo e acima de tudo útil, o qual deve circular e alcançar um maior número de pessoas.

A utilização do número de publicações pelos órgãos responsáveis pelo financiamento de estudos, para a definição acerca da distribuição de recursos e bolsas de estudos, está gerando uma busca desenfreada em adquirir mais publicações sem uma preocupação mínima (em alguns casos) em se buscar algo inovador e que vá agregar a ciência como um todo. (REGO, 2014; p.328).

Assim, alguns estudiosos afirmam que a disseminação do autoplágio seria em decorrência da cobrança sistêmica da produção cientifica, esquecendo-se, muitas vezes, da qualidade das publicações, gerando um fenômeno denominado produtivismo.

Acerca do produtivismo acadêmico, posiciona-se Teresa Cristina Rego (2014, p.328):

De fato, os cenários indicam os reflexos de um processo perverso que, de uma forma ou de outra, tem afetado os pesquisadores, as universidades e as revistas do Brasil (assim como já ocorreu ou vem ocorrendo em diferentes partes do mundo), comumente reconhecido como produtivismo acadêmico: a obrigação de publicar em periódicos como indicador praticamente exclusivo para a avaliação da produção científica e da qualidade do pesquisador está levando a um conjunto preocupante de desdobramentos.4 Esses vão desde a instalação de climas de rivalidade e disputa entre colegas, acompanhada de uma busca cada vez mais frenética e desmedida por espaços editoriais qualificados por parte daqueles que estão nas universidades e outras instituições ligadas à produção do conhecimento, passando pela adoção acrítica dos mesmos critérios das ditas ciências duras - com maior tradição de publicar em periódicos e com pesquisas de caráter mais universal - para as ciências humanas e sociais (que produzem num outro ritmo) até a multiplicação de revistas inconsistentes. Como se não bastasse a profusão de artigos e periódicos problemáticos (caracterizados pela irregularidade na publicação e distribuição, endogenia de seu corpo editorial ou de autores, ausência ou deficiência em padrões de normalização, dificuldade de indexação em bases internacionais reconhecidas etc.), uma das mais recentes manifestações (e consequências) desse processo está relacionada às hoje propaladas e combatidas "más condutas na pesquisa", práticas frequentemente adotadas por aqueles que já podem ser chamados "reféns da produtividade. 
Nesse mesmo sentido manifesta-se Eduardo Diniz (2008, p.201-202).:

[...] nós, acadêmicos, sofremos imensa pressão para publicar uma quantidade cada vez maior de artigos. O mais perverso é que os sistemas de avaliação da produção científica estão muito bem desenhados para computar a "quantidade" produzida, embora haja muito menos consenso sobre como identificar a "qualidade" dessa produção. É daí que nasce o chamado "produtivismo", comportamento pernicioso para a evolução do conhecimento científico e que tem sido tema de constante debate na academia, gerando ótimos artigos, inclusive na $R A E$

Relata Thomas Massao Fairchild (2017, p.14) que a discussão em torno da produção de conhecimento encontra-se em segundo plano em relação às "más práticas":

Esses [desdobramentos do produtivismo acadêmico] vão desde a instalação de climas de rivalidade e disputa entre colegas, acompanhada de uma busca cada vez mais frenética e desmedida por espaços editoriais qualificados por parte daqueles que estão nas universidades e outras instituições ligadas à produção do conhecimento, passando pela adoção acrítica dos mesmos critérios das ditas ciências duras - com maior tradição de publicar em periódicos e com pesquisa de caráter mais universal - para as ciências humanas e sociais (que produzem num outro ritmo) até a multiplicação das revistas inconsistentes. [...] No Brasil e em várias partes do mundo, são crescentes os casos envolvendo más condutas em pesquisas científicas, como: manipulação, falsificação ou fabricação de dados ou de resultados, plágio, autoplágio (apresentação total ou parcial de textos já publicados pelo mesmo autor como se fossem inéditos), bem como a prática - bastante comum, diga- se de passagem - da coautoria de fachada.

Discute-se ainda se ao proibir que o autor recomece novo estudo tomando por base antigos manuscritos seus, atualizando-o, sem qualquer referência de autocitação, não seria uma forma de induzir o autor a não ser uma autoridade do assunto. Explica-se.

Nos tempos atuais, as editoras fazem uso de mecanismos capazes de detectar a identidade entre os textos já publicados. Assim, quando verificado similaridade entre os textos, os autores são muitas vezes "acusados" de autoplágio, gerando uma situação desagradável. Assim, receosos de sofrerem qualquer tipo de incriminação nesse sentido, em razão da exigência de textos inéditos, os estudiosos optam em seguir novos rumos.

Contudo, não se pode olvidar que o ser humano é um ser complexo, o qual acumula, ao longo do tempo, conhecimento e experiências. Caso o pesquisador dê continuidade ao mesmo estudo inevitavelmente fará menções a dados e termos já utilizados em material anterior.

Logo, é impossível o ser humano deletar o conhecimento acumulado ao longo dos anos. Logo, será detectada alguma identidade entre o que já foi publicado pelo autor a respeito daquele tema. E isso deveria ser encarado de forma positiva, porque permitiria que o cientista 
se aprofundasse no tema e tornasse um expert no assunto, contribuindo ainda mais para a sociedade.

Corroborando com o entendimento supra, valioso o ensinamento de René Descartes (1989, p.08), ao dispor que: "para chegar ao conhecimento é preciso passar pela escada, ir degrau a degrau, pois a verdade não nasce do cérebro humano, mas da experiência do homem". Para o filosofo, o conhecimento é um crescente, o qual adquire-se aos poucos, através das mais diversas experiências do homem e diversos campos da sua vida.

No entanto, não se pode olvidar os aspectos negativos do autoplágio, o qual é visto como má conduta do autor, em razão da apresentação de uma publicação redundante, equiparando tal conduta a plágio, descredibilizando a instituição a qual está vinculado o pesquisador. (KROKOSCZ, 2011).

Outros fazem analise do plágio à luz da ética, afirmando que deveria existir uma atuação mais efetiva das instituições de ensino. Vejamos entendimento de Marcelo Krokoscz (2011, p. 750):

\begin{abstract}
Essa linha de reflexão sobre o plágio (do ponto de vista da ética) parece ser a mais adotada por pesquisadores internacionais. McCord (2008, p. 42) defende que formas adequadas de enfrentamento do plágio têm a ver com o papel das próprias instituições de ensino e diz respeito à mudança da cultura institucional de "pegar trapaceiros" para a promoção da integridade acadêmica. O autor fundamenta-se em estudos que demonstram que políticas institucionais consistentes e apoiadas pelo corpo docente são mais eficazes se os próprios estudantes se percebem agindo de forma mais justa e sensata.
\end{abstract}

Dessa forma, deve-se combater qualquer tipo de produção acadêmica que não agregue conhecimento inovador e benéfico à sociedade, e que se limite a ruminar as informações já disseminadas no meio acadêmico. Porém, entende-se que cabe à Coordenação de Aperfeiçoamento de Pessoal de Nível Superior (CAPES) e ao Conselho Nacional de Desenvolvimento Científico e Tecnológico $(\mathrm{CNPq})$ regular e traçar limites mais claros acerca dos casos que efetivamente enquadram-se como autoplágio, posto que corre-se o risco de infringir o direito de personalidade à integridade intelectual do pesquisador, impossibilitandoo a dar continuidade a seus estudos, em razão da insegurança de ser "acusado" de autoplágio. 


\section{CONCLUSÃO}

Ao longo do presente estudo apresentou-se o autoplágio, contextualizando-o com o plágio, demonstrando que aquele é uma subespécie deste, traçando as peculiaridades de cada um dos fenômenos.

O primeiro consiste na utilização de forma total ou parcial de manuscritos já publicados pelo mesmo pesquisador como se inédito fosse. Ao passo que o plágio, corresponde à utilização de textos de terceira pessoa como se fosse seu, sem a identificação da citação, seja de forma direta ou indireta.

Verificou-se que, em que pese seja o autoplágio um instituto rechaçado no meio acadêmico, com a divulgação disseminada da exigência de autocitação quando um estudo anterior do autor relacionado ao mesmo tema seja utilizado, este não se encontra regulamentado na legislação pátria. Tal constatação, dá azo a divulgação de publicações superficiais, posto que os autores receosos de serem "acusados" de autoplágio, não se aprofundam sobre um mesmo tema.

Ademais, destacou-se que o autoplágio apesar de ser uma questão ética, muitas vezes é utilizado como forma de obter um favorecimento em razão da concorrência existente no meio acadêmico, em que fomenta-se cada vez mais a produção por meio de publicações, visando aumentar a avaliação da instituição perante a Coordenação de Aperfeiçoamento de Pessoal de Nível Superior (CAPES) e melhorar o prestigio da instituição no meio acadêmico e no mercado, e noutros casos busca-se apenas o recebimento de bolsas de estudos.

Constatou-se ainda a ineficiência das políticas utilizadas na exterminação do plágio e do autoplágio, posto que são fenômenos enraizados no meio acadêmico. Entende-se pela aniquilação de toda obra acadêmica que não apresente uma pesquisa inovadora à comunidade, sugerindo-se, para tanto, uma regularização a nível mundial, unificando-se os conceitos de tais institutos.

No que concerne ao autoplágio, recomenda-se a apresentação de um patamar máximo em que uma nova obra possa basear-se em estudos antigos do autor. Acredita-se que a ciência e a comunidade ganhariam com isso, já que traria mais segurança ao pesquisador que sentir-seia mais à vontade para aprofundar seus estudos sobre um tema, passando a ser um especialista no assunto.

Rev. de Pesquisa e Educação Jurídica | e-ISSN: 2525-9636 | Porto Alegre | v. 4 | n. 2 | p. 35 - 50 | Jul/Dez. 2018 
Por fim, enfrentou-se o autoplágio à luz do direito a integridade intelectual. Declinouse que o direito do autor se encontra dividido em dois parâmetros: direitos morais e direitos patrimoniais. O primeiro possui relação direta com o direito do autor de alterar e de se contrapor a qualquer modificação em seus escritos, e não pode ser negociado, sob pena de ser anulado.

Ao passo que os direitos de propriedade são disponíveis e, em regra, são negociados através de um contrato de cessão, adquirindo a editora/revista a propriedade do texto. Encontrase, geralmente, dentre as cláusulas contratuais a previsão da limitação do uso do texto, no todo ou em parte, por outra publicação.

Conclui-se, portanto, que a vedação ao autoplágio não afronta o direito personalíssimo à integridade intelectual, posto que o autor ao assinar contrato ou termo com revista ou editora, abre mão do seu direito de propriedade sobre o manuscrito, mantendo-se intacto apenas o seu direito moral sobre a obra.

\section{REFERENCIAS}

BITTAR, Carlos Alberto. Contornos Atuais do Direito do Autor. 2 ed. rev., atual., e ampl.São Paulo: Editora Revista dos Tribunais, 1999.

BRASIL, Planalto. Lei 9.610, de 19 de fevereiro de 1998. Legislação sobre Direitos Autorais. Diário Oficial da República Federativa do Brasil, Brasília, DF, 19 fev. 1998. Disponível em: http://www.planalto.gov.br/ccivil_03/Leis/L9610.htm. Acesso em: 28 mai. 2018.

BRASIL, Portaria PO-085-2011, de 05 de maio de 2011. Relatório da Comissão de Integridade de Pesquisa do Conselho Nacional de Desenvolvimento Científico e Tecnológico (CNPq). Brasília, DF, 05 mai. de 2011. Disponível em: http://www.cnpq.br/documents/10157/a8927840-2b8f-43b9-8962-5a2ccfa74dda. Acesso em: 28 mai. 2018.

CABRAL, Plinio. A Nova Lei de Direitos Autorais - Comentários - $4^{\text {a }}$ edição, São Paulo. Harbras, 2003.

CHINELLATO, Silmara Juny de Abreu. Notas sobre plágio e autoplágio. Revista do Instituto dos Advogados de São Paulo, São Paulo, v. 29, p. 305-328, jan./jun. 2012. p. 308.

COURY, Helenice. Integridade na Pesquisa e Publicação Cientifica. Revista Brasileira de Fisioterapia. São Carlos, v.16, n. 1, p. V - VI, jan./fev./2012.

DESCARTES, René. Regras para Direção do Espírito. Tradução: João Gama. Lisboa. Edições 70.1989. 
DINIZ, Eduardo. O Gato que Copia: Similariedade e Produção acadêmica na era Digital. Revista de Administração de Empresas, v.58, n. 2, mar-abril.2018.

Disponível em: http://www.ebah.com.br/content/ABAAAe0cUAG/direito-a-integridadeintelectual. Edições 70, 1989.

FAIRCHID, Thomas Massao. Production, productivism, plagiarism: notes on originality in language teaching research. Revista do Gel, v. 14, n. 1, p. 12-35, 2017, São Paulo.

FASB, André. Direito à integridade intelectual. Disponível em: http://www.ebah.com.br/content/ABAAAe0cUAG/direito-a-integridade-intelectual. Acesso em 24 de maio de 2018.

GAGLIANO, Pablo Stolze; PAMPLONA FILHO, Rodolfo. Manual de direito civil. Volume único. Saraiva Educação SA, 2018.

GOMES, Orlando. Introdução ao Direito Civil. Rio de Janeiro, Forense, 2000.

GUEVARA, A. J. H.; DIB, V . C. Da sociedade do conhecimento à sociedade da informação. São Paulo: Saraiva, 2007.

KROKOSCZ, Marcelo. Abordagem do plágio nas três melhores universidades de cada um dos cinco continentes e do Brasil. Rev. Bras. Educ. [online]. 2011, vol.16, n.48, pp.745-768. ISSN 1413-2478. http://dx.doi.org/10.1590/S1413-24782011000300011.

KROKOSCZ, Marcelo. Outras palavras: análise dos conceitos de autoria e plágio na produção textual científica no contexto pós-moderno. 2014. Tese (Doutorado em Educação) - Faculdade de Educação, Universidade de São Paulo, São Paulo, 2014. doi:10.11606/T.48.2016.tde-03102016-103125. Acesso em: 2018-05-28.

PERLINGIERI, Pietro. Perfis do Direito Civil - Introdução ao Direito Civil Constitucional. Ed. Renovar, 2002.

POSNER, Richard A. El Pequeño Libro Del Plagio. El Hombre del Tres, Madrid, 2013.

REGO, Teresa Cristina. Produtivismo, pesquisa e comunicação científica: entre o veneno e o remédio. Educação e Pesquisa, São Paulo, v. 40, n. 2, p. 325-346, abr.-jun. 2014.

SILVA, Hugo Gregório Mussi.A Origem E A Evolução Dos Direitos Da Personalidade E A Sua Tutela No Ordenamento Jurídico Brasileiro. 2016. Disponível em: http://www.egov.ufsc.br/portal/sites/default/files/5571-14924-1-pb.pdf. Acesso em 01 agos. 2018.

SIXTO, Luisa Webber Troian. Contrato de cessão de direitos autorais. Conteudo Juridico, Brasilia-DF: 19 nov. 2014.2 Disponivel em: <http://www.conteudojuridico.com.br/?artigos\&ver=2.50715\&seo=1>. Acesso em: 27 maio 2018. 
SPINAK, E. Ética editorial e o problema do plágio [online]. SciELO em Perspectiva, 2013 [viewed 06 May 2018]. Disponível em: https://blog.scielo.org/blog/2013/10/02/etica-editoriale-o-problema-do-plagio/. Acesso em 27 mai. 2018.

TEPEDINO, Gustavo. Temas de Direito Civil. $4^{\text {a }}$ edição revista e atualizada. Rio de Janeiro. Renovar, 2008.

VASCONCELOS, Sonia M. R. O plágio na comunidade científica: questões culturais e linguístcas. Cienc. Cult., São Paulo, v. 59, n. 3, p. 4-5, Sept. 2007 . Disponível em: $<$ http://cienciaecultura.bvs.br/scielo.php?script=sci_arttext\&pid=S000967252007000300002\&lng=en\&nrm=iso>. Acesso em: 12 Jun. 2018.

ZANINI, Leonardo Estevam de Assis. Notas sobre o plágio e a contrafação. Revista de Doutrina da $4^{\mathrm{a}}$ Região, Porto Alegre, n.81, dez. 2017. Disponível em: <http://revistadoutrina.trf4.jus.br/artigos/edicao081/Leonardo_Estevam_Zanini.html>. Acesso em: 24 maio 2018. 